Journal of the Electrochemical Society, Vol. 145, No. 6, 1998, pp. 2186-2198.

ISSN: (Print 0013-4651) (Online 1945-7111)

DOI: $10.1149 / 1.1838615$

http://www.electrochem.org/

http://scitation.aip.org/JES

http://scitation.aip.org/getpdf/servlet/GetPDFServlet?filetype=pdf\&id=JESOAN000145000006002186000001\&idty pe $=$ cvips \&prog $=$ normal

(C) The Electrochemical Society, Inc. 1998. All rights reserved. Except as provided under U.S. copyright law, this work may not be reproduced, resold, distributed, or modified without the express permission of The Electrochemical Society (ECS). The archival version of this work was published in Journal of the Electrochemical Society, Vol. 145, No. 6, 1998, pp. 2186-2198.

\title{
Pitting Corrosion of Metals A Review of the Critical Factors
}

\section{G. S. Frankel}

Fontana Corrosion Center, The Ohio State University, Columbus, Ohio

\begin{abstract}
Pitting corrosion is localized accelerated dissolution of metal that occurs as a result of a breakdown of the otherwise protective passive film on the metal surface. This paper provides an overview of the critical factors influencing the pitting corrosion of metals. The phenomenology of pitting corrosion is discussed, including the effects of alloy composition, environment, potential, and temperature. A summary is then given of studies that have focused on various stages of the pitting process, including breakdown of the passive film, metastable pitting, and pit growth.
\end{abstract}

\section{Introduction}

Many engineering alloys, such as stainless steels and Al alloys, are useful only because of passive films, which are thin (nanometer scale), oxide layers that form naturally on the metal surface and greatly reduce the rate of corrosion of the alloys. Such passive films, however, are often susceptible to localized breakdown resulting in accelerated dissolution of the underlying metal. If the attack initiates on an open surface, it is called pitting corrosion; at an occluded site it is called crevice corrosion. These closely related forms of localized corrosion can lead to accelerated failure of structural components by perforation, or by acting as an initiation site for cracking. This paper summarizes the effects of a number of factors in pitting corrosion. It is intended to be an overview of the critical issues and not a comprehensive review of the entire field.

Pitting corrosion has been studied for several decades by many researchers and detailed information is available in a book ${ }^{1}$ and several conference proceedings. ${ }^{2-7}$ Considerable understanding of the pitting phenomenon has been generated, but an in-depth description of many steps is still lacking. Fundamental studies typically have focused on one of the following stages of the pitting process: characteristics of the passive film, the earliest stages of passive film breakdown, the growth of metastable pits (which grow to about the micron scale and then repassivate), and the growth of larger, stable pits. Each of these stages is discussed in turn. First, however, the phenomenology of pitting is be reviewed.

It should be noted that, whereas localized dissolution following breakdown of an otherwise protective passive film is the most common and technologically important type of pitting corrosion, pits can form under other conditions as well. For instance, pitting can occur during active dissolution if certain regions of the sample are more susceptible and dissolve faster 
than the rest of the surface. ${ }^{1}$ Another example is the pitting of GaAs that has been found in the absence of a surface oxide layer. ${ }^{8}$ In that case, however, a space-charge layer in the semiconductor played the role of a passive film by protecting most of the surface, but breaking down locally. This review concentrates on the better known and widely studied phenomenon of pitting corrosion of passive metals.

\section{Phenomenology of Pitting}

Environmental effects and local chemistry development.-Pitting corrosion will only occur in the presence of aggressive anionic species, and chloride ions are usually, although not always, the cause. The severity of pitting tends to vary with the logarithm of the bulk chloride concentration. ${ }^{9}$ The reason for the aggressiveness of chloride has been pondered for some time, and a number of notions have been put forth. Chloride is an anion of a strong acid, and many metal cations exhibit considerable solubility in chloride solutions. ${ }^{10}$ Chloride is a relatively small anion with a high diffusivity, it interferes with passivation, and it is ubiquitous as a contaminant.

The presence of oxidizing agents in a chloride-containing environment is extremely detrimental, and will further enhance localized corrosion. In fact, there is an ASTM standard for testing the pitting resistance of materials by exposing them to $6 \% \mathrm{FeCl}_{3}$ solution that combines both high chloride content and high oxidizing power. ${ }^{11}$ It is shown below that the increase in potential associated with oxidizing agents enhances the likelihood of pitting corrosion.

Pitting is considered to be autocatalytic in nature; once a pit starts to grow, the conditions developed are such that further pit growth is promoted. The anodic and cathodic electrochemical reactions that comprise corrosion separate spatially during pitting. The local pit environment becomes depleted in cathodic reactant (e.g., oxygen), which shifts most of the cathodic reaction to the boldly exposed surface where this reactant is more plentiful. The pit environment becomes enriched in metal cations and an anionic species such as chloride, which electromigrates into the pit to maintain charge neutrality by balancing the charge associated with the cation concentration. The $\mathrm{pH}$ in the pit is lower owing to cation hydrolysis

$$
\begin{aligned}
\mathrm{Me}^{2+}+2 \mathrm{H}_{2} \mathrm{O} \rightarrow \mathrm{Me}(\mathrm{OH})^{+}+\mathrm{H}^{+} & \\
+ & \mathrm{H}_{2} \mathrm{O} \rightarrow \mathrm{Me}(\mathrm{OH})_{2}+2 \mathrm{H}^{+}[1]
\end{aligned}
$$

and the absence of a local cathodic reaction. The acidic chloride environment thus generated in pits is aggressive to most metals and tends to propagate the pit growth.

A number of researchers have studied the local chemistries that form in pits using a range of techniques. ${ }^{12,13}$ One way to isolate the pit solution is by rapid freezing of the electrode in liquid nitrogen, removal of the surface excess, and subsequent thawing. This approach was used, for instance, to study the $\mathrm{pH}$ in $\mathrm{Al}$ pits $^{14}$ and the chloride concentration in pits in stainless steel. ${ }^{15}$ It is also possible to extract solution from an artificial pit electrode (also called a onedimensional pit or lead-in-pencil electrode), which is a wire imbedded in an insulator such as epoxy. This technique allows a considerable volume of pit electrolyte to be analyzed. Extraction of reasonable amounts of electrolyte is also possible from crevices and cracks, ${ }^{12,13}$ both of which can develop local chemistries similar to those found in pits. Such solutions have been analyzed by the full range of available analytical techniques. Different techniques allow determination of 
cation and anion concentration, oxidation state, and complexation. Finally, it is possible to insert microelectrodes into pits, cracks, and crevices. ${ }^{12,13}$ Once the local solution composition is fully characterized, it is possible to mimic the local environment by reconstituting it in bulk form from reagent grade chemicals, and then determining the electrochemical behavior of a normal-sized metal electrode in that environment. The use of microelectrodes and analysis of electrolyte extracted from a local environment, however, provide no information on gradients that exist within pits. In order to determine these gradients, it is necessary to perform in situ measurements, as has been done using X-ray absorption spectroscopy on artificial crevices. ${ }^{16}$

A detailed analysis of the influence of pit chemistry changes on pit growth and stability was provided by Galvele. ${ }^{10,17}$ The concentration of various ionic species at the bottom of a model one-dimensional pit geometry was determined as a function of current density based on a material balance that considered generation of cations by dissolution, outward diffusion, and thermodynamic equilibrium of various reactions such as cation hydrolysis, Eq. 1. Galvele found that a critical value of the factor $x \cdot i$, where $x$ is pit depth and $i$ is current density, corresponded to a critical pit acidification for sustained pit growth, Fig. 1.

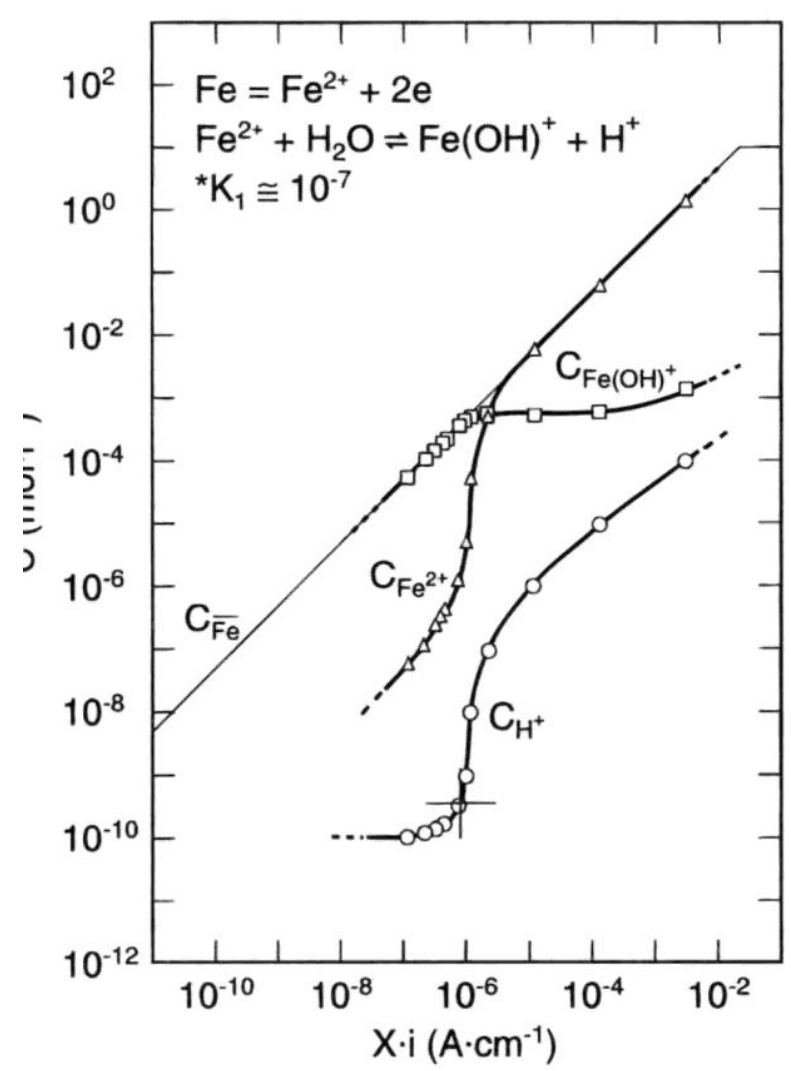

Fig. 1. Concentrations of $\mathrm{Fe}^{2+}, \mathrm{Fe}(\mathrm{OH})^{+}$, and $\mathrm{H}^{+}$as a function of the product of the depth $\mathrm{x}$ and current density $i$ in a one-dimensional pit. ${ }^{17}$ Reprinted with permission.

This value can be used to determine the current density required to initiate or sustain pitting at a defect of a given size. The model of pit chemistry based on reaction, hydrolysis, diffusion, and migration is a proper approach to the problem. The focus of Galvele's work on pit acidification, however, may not be totally appropriate since, at least for stainless steel, the local chloride 
concentration is probably more important than the local $\mathrm{pH}$ in terms of stabilizing pit growth and preventing repassivation. On the other hand, other factors describing the severity of the local environment, such as chloride concentration, will roughly scale with acidity, so a critical value of $x \cdot i$ may in fact accurately predict pit stability.

As the pit current density increases, the ionic concentration in the pit solution increases, often reaching supersaturation conditions. A solid salt film may form on the pit surface, at which point the ionic concentration would drop to the saturation value, which is the value in equilibrium with the salt layer. Under these conditions, the pit growth rate is limited by mass transport out of the pit. Salt films are not required for pit stability (though some have suggested that they are ${ }^{14,18-22}$ ), but they enhance stability by providing a buffer of ionic species that can dissolve into the pit to reconcentrate the environment in the event of a catastrophic event, such as the sudden loss of a protective pit cover. Under mass-transport-limited growth, pits will be hemispherical with polished surfaces. In the absence of a salt film (at lower potentials), pits may be crystallographically etched or irregularly shaped in some other fashion.

Potential.-Electrochemical studies of pitting corrosion have found that characteristic potentials exist. Stable pits form at potentials noble to the pitting potential, $E_{\mathrm{P}}$, and will grow at potentials noble to the repassivation potential, $E_{\mathrm{R}}$, which is lower than $E_{\mathrm{P}}$. (Note that several other names and subscripts have been used to describe these characteristic potentials. Furthermore, the terms "noble" and "active" are used in this paper to indicate relative locations on the potential scale with noble being in the direction of $\mathrm{Au} / \mathrm{Au}^{3+}$ and active being in the direction of $\mathrm{K} / \mathrm{K}^{+}$) During upward scanning in a cyclic polarization experiment such as is shown schematically in Fig. 2, a stable pit starts growing at $E_{\mathrm{P}}$ where the current increases sharply from the passive current level and, upon reversal of the scan direction, repassivates at $E_{\mathrm{R}}$ where the current drops back. It is generally considered that materials exhibiting higher values of $E_{\mathrm{P}}$ and $E_{\mathrm{R}}$ are more resistant to pitting corrosion, and cyclic polarization experiments are commonly used for this purpose. A correlation has been found such that metals with low experimentally determined pitting potentials have a higher tendency to form pits naturally at open circuit. ${ }^{9}$ The difference between $E_{\mathrm{P}}$ and $E_{\mathrm{R}}$, which is related to the extent of hysteresis in a cyclic potentiodynamic polarization curve, has also been considered to be a measure of the susceptibility to localized corrosion. ${ }^{23,24}$ However, there is abundant experimental evidence suggesting that consideration of this simplistic interpretation of the characteristic potentials alone is insufficient for the development of a fundamental understanding of the mechanism of pitting corrosion. For instance, the potentiodynamically determined pitting potential of most materials exhibits a wide experimental scatter, of the order of hundreds of millivolts. Furthermore, $E_{\mathrm{P}}$ is in many cases a function of experimental parameters such as potential scan rate. As described below, so-called metastable pits initiate and grow for a period at potentials well below the pitting potential, ${ }^{25}$ which provides evidence in contradiction to the definition of the pitting potential as being the potential above which pits initiate. The meaning of the repassivation potential has also been called into question. Wilde showed that $E_{\mathrm{R}}$ of ferritic stainless steel decreased (i.e., moved in the active direction) with increasing values of the current density at which the potential scan direction was reversed. $^{24,26}$ So deeper pits apparently repassivated at lower potentials. In contrast, the repassivation potential for pits in $\mathrm{Al}$ seemed to be relatively independent of the extent of prior pit growth for a limited number of experiments. ${ }^{27}$ Some have found a similar lack of dependence of $E_{\mathrm{R}}$ on prior growth for pits in stainless steel, but only after the passage of large charge densities. $^{28}$ Thompson and Syrett have suggested that the highest observed repassivation 
potential is the critical potential in pitting. ${ }^{29}$ They indicated that this value is associated with repassivation of very small pits, and is close to the lowest observed value of pitting potential. No means was suggested, however, for accurate and reproducible determination of this critical potential.

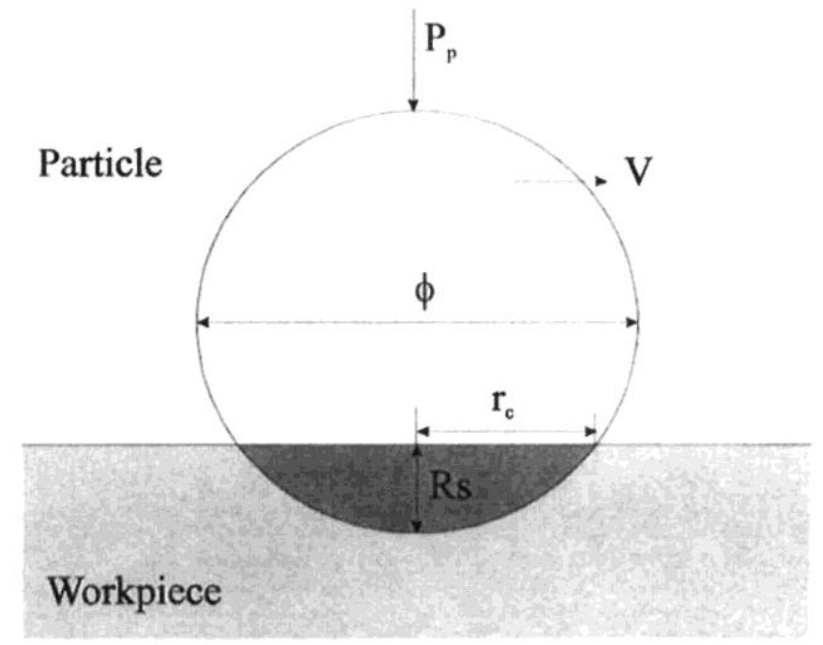

Fig. 2. Schematic diagram of the potentiodynamic polarization curve of a spontaneously passive metal that is susceptible to pitting corrosion.

The existence of a critical potential for pitting has been explained in a variety of ways based on the roles of various critical factors. For instance, the critical acidification theory predicts that a critical potential will be required to initiate pitting since the pit current density, and thus the product $x \cdot i$ for a defect of a given size $x$, will increase with increasing applied potential. ${ }^{17}$ Similarly, a consequence of the concept that chloride adsorption is responsible for passive film breakdown is the idea that the driving force for adsorption will increase as the potential increases. Other explanations are given below.

Alloy effects. - The alloy composition and microstructure can have strong effects on the tendency for an alloy to pit. ${ }^{1}$ Certainly $\mathrm{Cr}$ concentration plays the dominant role in conferring passivity to ferrous alloys. The pitting potential was correspondingly found to increase dramatically as the $\mathrm{Cr}$ content increased above the critical $13 \%$ value needed to create stainless steel. $^{30}$ Increasing concentration of $\mathrm{Ni}$, which stabilizes the austenitic phase, moderately improves the pitting resistance of $\mathrm{Fe}-\mathrm{Cr} .{ }^{30}$ Small increases in certain minor alloying elements, such as $\mathrm{Mo}$ and $\mathrm{N}$ in stainless steels, can greatly reduce pitting susceptibility. ${ }^{1}$ Mo is particularly effective, but only in the presence of Cr. Various explanations have been given for the large influence of Mo on stainless steel corrosion. Mo was not found in the passive film using AES or XPS, ${ }^{31,32}$ but is enriched in the surface film formed in the active region. ${ }^{32}$ It was suggested that Mo acts by adsorbing on the surface as molybdate ${ }^{31}$ or by blocking active sites during active dissolution. Other theories include enhancement of the cation-selective properties of the passive film ${ }^{33}$ and reducing the flux of cationic vacancies. ${ }^{34}$ Mo ennobles the pit dissolution kinetics, effectively decreasing the pit current density at a given potential. ${ }^{35}$ It has also been suggested that Mo counteracts the deleterious effect of $S$ (see below) by enriching at the surface, bonding to 
adsorbed S, and then dissolving. ${ }^{36}$ The majority of researchers seem to favor the notion that Mo influences localized corrosion via some kind of dissolution and pit growth consideration. Small amounts of other elements, such as $\mathrm{N}$ and $\mathrm{W}$, also have a strong influence on the pitting resistance of stainless steels. ${ }^{37,38}$ It was suggested that $\mathrm{N}$ alloying strongly affects the anodic dissolution kinetics in the range of 3-4 M HC1. ${ }^{39}$

Since $\mathrm{Al}$ is a very active and reactive metal, the homogeneous addition of almost any metal (except $\mathrm{Mg}$ and $\mathrm{Zn}$ ) into $\mathrm{Al}$ alloys results in an increase in pitting potential. ${ }^{40-45}$ It is, of course, essential that the structure remain single phase. The pitting potential of binary Al-Cu alloys increased with $\mathrm{Cu}$ concentration as long as the $\mathrm{Cu}$ was in solid solution. ${ }^{46}$ Since the equilibrium solubility in $\mathrm{Al}$ of many metals is exceedingly small, other alloying additions tend to generate second-phase intermetallic particles. However, using rapid quenching preparation techniques, such as physical vapor deposition (e.g., sputter deposition), it is possible to alloy Al homogeneously with a wide range of elements. The resulting microstructure is a non-equilibrium single phase that is either nanocrystalline or amorphous. Sputter-deposited Al alloys have been found to exhibit dramatic increases in pitting potential. ${ }^{40-44} \mathrm{~A}$ few atomic percent of metal solute (e.g., Cr, Ta, Nb, W, Mo, Ti) will increase $E_{\mathrm{P}}$ by around $200 \mathrm{mV}$, and increases of over $1 \mathrm{~V}$ are possible with higher amounts of alloying. Explanations for the improvement in pitting resistance conferred on $\mathrm{Al}$ by this nonequilibrium alloying have been offered based on influences on the composition and protectiveness or $\mathrm{pH}$ of zero charge of the passive film, ${ }^{47}$ the solubility of dissolved species in the pit solution, ${ }^{48}$ enrichment of the solute species at the active surface in a pit, ${ }^{49}$ and decreases in the pit dissolution kinetics. ${ }^{50}$ More on this is given below.

Pits almost always initiate at some chemical or physical heterogeneity at the surface, such as inclusions, second phase particles, solute-segregated grain boundaries, flaws, mechanical damage, or dislocations. ${ }^{1}$ Most engineering alloys have many or all such defects, and pits will tend to form at the most susceptible sites first. Pits in stainless steels are often associated with $\mathrm{MnS}$ inclusions, which are found in most commercial steels. The role of $\mathrm{MnS}$ inclusions in promoting the breakdown and localized corrosion of stainless steels has been recognized for some time. ${ }^{51,52}$ The explanations have focused on dissolution products of the sulfides. It has been suggested that sulfides oxidize to form sulfate and acid, ${ }^{51}$ elemental sulfur, ${ }^{52}$ or thiosulfate, ${ }^{53}$ and also that they chemically dissolve to form $\mathrm{H}_{2} \mathrm{~S} .{ }^{51}$ A recent analysis of crevice solutions found that sulfide was the predominant sulfur-containing species with some sulfite forming in wellestablished crevices. ${ }^{54}$ Many different forms of dissolved sulfur species can decrease the pitting potential of stainless steel in chloride solutions, ${ }^{55}$ and it has been suggested that sulfur can enrich at the surface to lower the activation energy for dissolution and inhibit passivation. ${ }^{56}$

Pits in Al alloys are typically associated with intermetallic particles. ${ }^{57,58}$ As described above, $\mathrm{Cu}$ additions to $\mathrm{Al}$ resulted in improvements in pitting resistance when the $\mathrm{Cu}$ was in solid solution. However, when particles of the intermetallic 9-phase $\left(\mathrm{Al}_{2} \mathrm{Cu}\right)$ formed, the resistance to pitting decreased back to the range of $\mathrm{Al}$ alloyed with little $\mathrm{Cu} .{ }^{46}$ The formation of GP zones had no effect on pitting potential in that study. On the other hand, another study found that microsegregation of $\mathrm{Cu}$ and $\mathrm{Fe}$ impurities at nodes in high purity $\mathrm{Al}$ was sufficient to increase the tendency for pitting corrosion at open circuit. ${ }^{59}$ The decrease in pitting potential with formation of 6-phase was explained by the existence of a $\mathrm{Cu}$ depleted region near the particles. ${ }^{46}$ This region would have a lower pitting potential, so pits would tend to form there first.

Under potentiostatic control, the potentiostat provides a growing pit as much current as is needed to maintain the applied potential. At open circuit under free corrosion conditions, however, the anodic reaction in a pit is fed by current from cathodic areas outside of the pit, and 
pit growth can be cathodically limited. The aluminum oxide surface is, in general, not very catalytic for cathodic reactions. $\mathrm{Cu}$ - or Fe-rich particles are noble to the $\mathrm{Al}$ matrix, and exhibit enhanced cathodic kinetics. ${ }^{60}$ In fact, metallic $\mathrm{Cu}$ has been found in the oxide film formed on a bulk 9-phase sample. ${ }^{60}$ If the potential of the Al matrix near a noble particle should increase above the pitting potential, pitting would ensue. Certainly, any increase in the local potential will increase the likelihood for pitting to occur. The passive $\mathrm{Al}$ in the matrix surrounding the particles should be rather polarizable, but the small noble particle/matrix area ratio is not conducive to a strong galvanic influence of the particles, which raises questions about the exact role of these particles. It has been suggested that pits nucleate at noble particles in Al because of alkaline dissolution of the matrix at the particle interface where the $\mathrm{pH}$ of the solution is increased owing to the cathodic reaction on the particle surface. ${ }^{61}$ In this scenario, however, it is difficult to understand how a trench initiated by alkaline dissolution would convert to an acidic pit. Another factor that may enhance the initiation of attack at the boundary of an inclusion or intermetallic particle and matrix is the possibility of a pre-existing crack or defect at that interface. Recently, the influence of intermetallic particles on the open-circuit corrosion of Al alloy 2024 in a corrosive environment such as salt fog has been addressed. ${ }^{62}$ It was found using careful surface preparation that the largest class of particles in 2024-T3 is the $S$ phase $\left(\mathrm{Al}_{2} \mathrm{CuMg}\right)$ rather than $\theta$ phase. The S-phase is active to the matrix, and it was suggested that first $\mathrm{Mg}$ and then $\mathrm{Al}$ dissolve out of S-phase particles by a dealloying mechanism leaving a porous $\mathrm{Cu}$-rich sponge. Decomposition and disintegration of this sponge results in distribution across the sample surface of both metallic and oxidized $\mathrm{Cu}$. The area ratio of such a structure would then be firmly in favor of a galvanic driving force for localized corrosion of the exposed $\mathrm{Al}$ matrix.

Pits often grow with a porous cover. This cover can make visual detection extremely difficult, so that the awareness of the severity of attack is overlooked, and the likelihood of catastrophic failure is enhanced. The pit cover might be a thick precipitated product layer that forms as the concentrated and acidic pit solution meets the bulk environment, which might be neutral or limited in water, as in the case of atmospheric corrosion. Small pits in stainless steels often have a pit cover that is a remnant of the undermined passive film. ${ }^{25}$ Larger pits in stainless steel can be covered by a layer with a considerable thickness of metal that is detached from the rest of the metal sample. ${ }^{63}$ These covers make optical detection extremely difficult since they remain reflective. A short exposure to ultrasonic agitation, however, removes the cover and reveals the whole pit diameter.

Temperature.-Temperature is also a critical factor in pitting corrosion since many materials will not pit at a temperature below a certain value, which may be extremely sharp and reproducible. ${ }^{64-70}$ This effect can be seen either by varying the temperature at a range of fixed applied potentials, or varying the potential for a range of constant temperature experiments. At low temperatures, extremely high breakdown potentials are observed, corresponding to transpassive dissolution, not localized corrosion. Just above the critical pitting temperature (CPT), pitting corrosion occurs at a potential that is far below the transpassive breakdown potential. This value of CPT is independent of environmental parameters and applied potential over a wide range and is a measure of the resistance to stable pit propagation. ${ }^{64}$ At higher temperatures, the pitting potential decreases with increasing temperature and chloride concentration. Pit initiation considerations play a role in this region. ${ }^{64}$ It has been suggested by Laycock and Newman ${ }^{70}$ that the CPT is associated with the dual role of a salt film in either stabilizing pit growth by providing a buffer of solute (at high temperatures) or facilitating 
repassivation (at low temperatures) as has been discussed in detail by Beck. ${ }^{20}$ Critical pitting temperatures for many stainless steels are in the range of $10-100^{\circ} \mathrm{C} .{ }^{64}$ The $\mathrm{CPT}$ can be used, like pitting potential, as a means for ranking susceptibility to pitting corrosion; the higher the CPT, the more resistant the alloy to pitting. ${ }^{64}$ On the other hand, Al alloys do not exhibit a CPT in aqueous chloride solutions at temperatures down to $0^{\circ} \mathrm{C} .{ }^{71}$

Stochastics. - Since pitting events are relatively rare and unpredictable, pit initiation may be considered to be random in nature. Stochastic approaches have been developed to handle this randomness and the large scatter typically observed in measurements of pitting potential and induction time (which is the time for a stable pit to form following a sudden increase in potential into the pitting range, or following the injection of chloride into a nonaggressive solution). Stochastic approaches used to address metastable pits are discussed later in this paper. Shibata showed that a large ensemble of pitting potential values follows a normal distribution, suggesting random variation, Fig. $3 .^{72}$ The probability for pitting was determined by

$$
P(E)=n /(1+N)
$$

where $N$ is the total number of samples studied, and $n$ is the number of samples that had pitted at a potential of $E$ or lower. The potential at $P=0.5$ is a representative value for a given material and surface preparation. Induction times at a given potential were also measured, and the survival probability, $P(t)$, was determined using Eq. 2, except that $n$ was the number of samples that had pitted by time $t$ after application of the potential. The pit generation rate, $\lambda$ was shown to be given by

$$
\lambda(t)=-d\{\ln P(t)\} / d t
$$

Three pit generation rates were found at successive time periods, with the second period exhibiting the highest rate. ${ }^{72}$

Inhibition of pitting.-Pitting can be inhibited by the same approaches that are commonly used to reduce corrosion in general. All of the factors described above can be used to mitigate pitting corrosion: environment, alloy composition and structure, potential, and temperature. Various chemicals, when added to corrosive solutions, will inhibit pitting. ${ }^{1}$ Common inorganic inhibitors include sulfates, nitrates, chromates, and molybdates. Some, such as sulfate, may act simply by providing supporting electrolyte that reduces the migration of $\mathrm{Cl}^{-}$into the pit. It was suggested that nitrate may reduce inside pits in $\mathrm{Al}$, consuming protons and thereby increasing $\mathrm{pH} .{ }^{73}$ Others may adsorb at active sites, or reduce pit growth kinetics.

High strength Al alloys, which are susceptible to pitting owing to the influence of $\mathrm{Cu}$ containing intermetallic particles, are often protected using a system of coatings. The standard coating system uses a chromate conversion layer covered by organic paint coats. The primer coat might contain chromate pigments for further corrosion protection. The chromate conversion layer is a mixed Al-Cr oxide film formed by immersion into a chromate-containing bath in which the following reaction occurs ${ }^{74,75}$

$$
\mathrm{Cr}_{2} \mathrm{O}_{7}^{2-}+8 \mathrm{H}^{+}+2 \mathrm{Al} \rightarrow 2 \mathrm{Al}^{3+}+2 \mathrm{Cr}(\mathrm{OH})_{3}+\mathrm{H}_{2} \mathrm{O}
$$


Chromate conversion layers also contain some amount of unreduced chromate ions. It is considered that the chromate retained in the coating is critical for providing a self-healing capability ${ }^{74,75}$ Chromate-coated samples scratched to the substrate and exposed to a corrosive environment such as a salt spray will usually not exhibit severe corrosion at the scratch. This protection is thought to result from chromate in the conversion coating dissolving into the local environment and blocking the dissolution reaction by reducing according to the same reaction that occurs when the coating forms, Eq. 4. Chromate pigment in primer should act the same way to protect a scratched area. Owing to the carcinogenic nature of chromate, considerable effort has been put into developing an equally effective and environmentally friendly replacement system. However, nothing developed to date is as effective as chromate for reducing the corrosion of high strength $\mathrm{Al}$ alloys. ${ }^{76}$

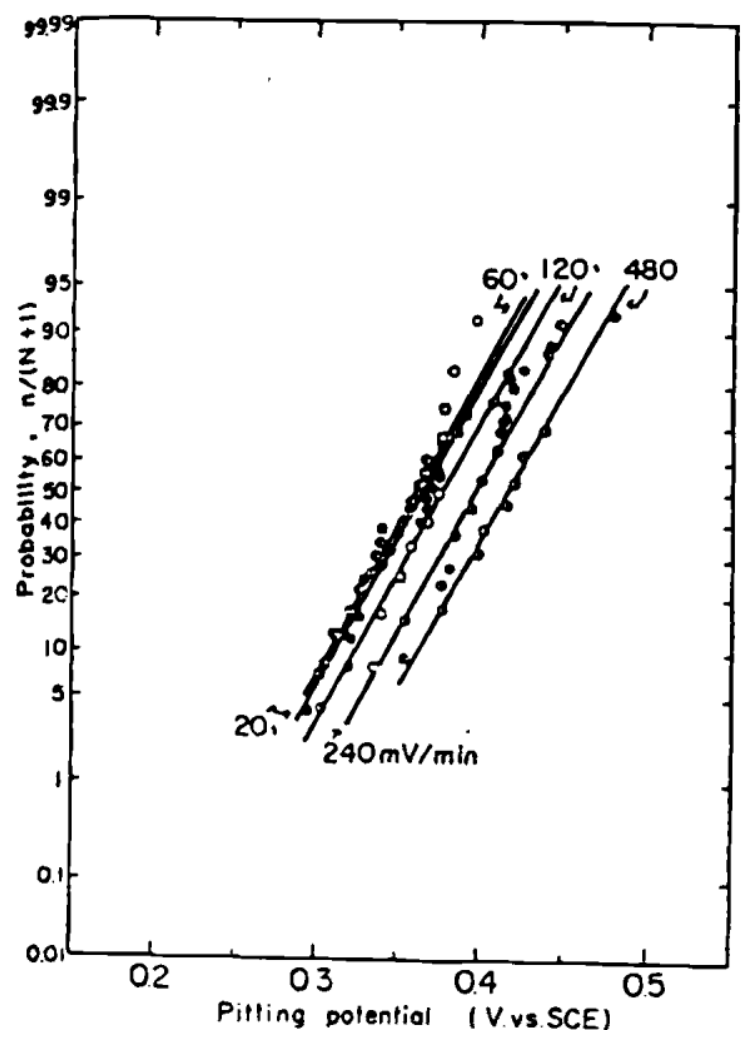

Fig. 3. Normal probability plot of the pitting potential of 304 stainless steel tested at different potential scan rates. From Ref. 72, T. Shibata and T. Takeyama, Corrosion, 33, 243 (1977).

\section{Stages of Pitting}

In this section, the various stages of pitting are discussed in order, from passive film breakdown, to metastable pitting, to pit growth. Any of these stages may be considered to be the most critical. For instance, once the passive film breaks down and a pit initiates, there is a possibility that a stable pit will grow. The full range of available spectroscopic and analytical techniques has been applied to the study of the structure and composition of passive films in a hope to predict and understand pit initiation. To those who prefer the surface science approach, for example, it is often assumed that alloying affects localized corrosion via changes in the 
composition and structure of the passive film. According to this view, pit growth is considered to be well understood and to offer little in the way of fundamental understanding of the phenomenon of pitting. On the other hand, others feel that pit growth is pivotal and often controls the pitting process, since pits will not initiate if they cannot grow at least for a short while. It is considered that the passive state is required for pitting to occur, but details of the passive film composition and structure play a minor role in the pitting process. This view is supported by the fact that many observations of pitting tendency can be fully accounted for by growth considerations. Furthermore, pit growth is critical in practical applications of failure prediction. Finally, the metastable pitting stage may be thought to be the most important since only pits that survive this stage become stable growing pits. Metastable pits exist on the edge of stability. Studies of metastable pits can therefore provide insight into fundamental aspects of pitting since both initiation and stability are key factors in metastable pitting.

Passive film breakdown. - The breakdown of the passive film and very initiation of the pitting process is probably the least understood aspect of the pitting phenomenon. Breakdown is a rare occurrence that happens extremely rapidly on a very small scale, making direct observation extraordinarily difficult. The passive film is often drawn schematically as a simple inert layer covering the underlying metal and blocking access of the environment to the metal. The reality is, of course, much more complicated. Depending on alloy composition, environment, potential, and exposure history, this film can have a range of thickness, structure, composition, and protectiveness. Typical passive films are quite thin, and support an extremely high electric field (on the order of $10^{6}$ to $10^{7} \mathrm{~V} / \mathrm{cm}$ ). The passage of a finite passive current density is evidence of continual reaction of the metal to result in film thickening, dissolution into the environment, or some combination of the two. The view of the passive film as being a dynamic, rather than static, structure is critical to the proposed mechanisms of passive film breakdown and pit initiation.

Theories for passive film breakdown and pit initiation have been categorized in three main mechanisms that focus on passive film penetration, film breaking, or adsorption, Fig. 4 . $^{77,78}$ As with most such situations, different mechanisms or combinations of these mechanisms may be valid for different metal/environmental systems. These mechanisms are described below in terms of pure metal systems. As mentioned above, however, pits in real alloys are most often associated with inclusions or second-phase particles.

Penetration mechanisms for pit initiation, Fig. 4a, involve the transport of the aggressive anions through the passive film to the metal/oxide interface where aggressive dissolution is promoted. ${ }^{79}$ Anion migration would be assisted by the high electric field in the film. The penetration mechanism is supported by the existence of an induction time for pitting following the introduction of chloride into an electrolyte. On the other hand, estimated induction times based on expected values of anion transport rates exceeded measured values by many orders of magnitude. ${ }^{79}$ Marcus and Herbelin found chloride present in passive films on Ni using careful XPS and radiotracer measurements. ${ }^{80} \mathrm{~A}$ critical concentration of chloride in the inner oxide portion of the passive film was associated with film breakdown and pit initiation. Others, however, have found no evidence of chloride in passive films. ${ }^{78,81}$

A related model for passive film breakdown is an outgrowth of the point-defect model developed by Macdonald and coworkers to describe passive film growth by the movement of point defects under the influence of an electrostatic field. ${ }^{82}$ The major point defects in an oxide film are assumed to be electrons, holes, and metal and oxide vacancies. Transport of vacancies 
across the film controls the film growth according to this view. The point-defect model has been used to explain pit initiation by assuming that aggressive ion (chloride) adsorption and incorporation at the outer surface of the barrier oxide layer results in the formation of cationic vacancies. ${ }^{83}$ These vacancies diffuse to the metal/oxide surface where they are annihilated by the oxidative injection of cations from the metal. However, if the flux of vacancies is larger than can be accommodated by oxidation, the vacancies will condense at the metal/film interface to form a void that is the first step in the pitting process according to this model. The point-defect model has been fitted to experimental data describing the statistical distribution of pitting potentials, the induction time for pitting, and the influence of alloying on the pitting potential. ${ }^{34}$ Interestingly, the pitting potential and induction time relate to pit stability and growth rather than pit initiation, since it is well known that metastable pits initiate at potentials far below the pitting potential and during the induction time prior to stable pit growth. Predictions from the point-defect model have yet to be compared to experimental measurements of the earliest stages of pit formation despite the fact that the model is based on phenomena occurring at the nanometer level. Other criticisms of the point-defect model have focused on the handling of the electrode potential and its role in influencing vacancy concentration and migration. ${ }^{78}$

Adsorption theories of initiation, Fig. $4 \mathrm{~b}$, were first based on the notion of competitive adsorption of chloride ions and oxygen. ${ }^{84}$ It is now known that the passive film is at least several monolayers thick rather than just an adsorbed oxygen layer. However, aspects of the adsorption model are still relevant. For instance, exposure of Fe to chloride and other halides caused thinning of the passive film based on XPS measurements, even under conditions where a pit had not formed, as a result of what was described as catalytically enhanced transfer of cations from the oxide to the electrolyte. ${ }^{78}$ On the other hand, another study using SIMS found that there was no difference in oxide thickness on $\mathrm{Fe}$ samples prepassivated in borate solution and then galvanostatically anodized at $5 \mu \mathrm{A} / \mathrm{cm}^{2}$ in solutions with or without $\mathrm{Cl}^{-}$. ${ }^{81}$ Interestingly, no $\mathrm{Cl}^{-}$ was found to be incorporated into the oxide during this treatment either. When thinning occurs locally because of some local adsorbed species, the local electric field strength will increase, which may eventually lead to complete breakdown and the formation of a pit. $^{79}$

Pit initiation by a film-breaking mechanism, Fig. 4c, considers that the thin passive film is in a continual state of breakdown and repair. ${ }^{85,86}$ Mechanical stresses at weak sites or flaws resulting from electrostriction and surface tension effects may cause the local breakdown events, which rapidly heal in nonaggressive environments. In fact, the background passive current density may come from a summation of many such breakdown and repair events. In chloridecontaining solutions, however, there would be a lower likelihood for such a breakdown to heal because of the inhibition of repassivation by chloride. The film-breaking model really involves initiation based on pit growth stability. It assumes that breakdown will always occur, albeit at a rate that depends on many factors related to the passive film properties. However, according to this model, breakdown will only lead to pitting under conditions where pit growth is possible. 
a) Penetration Mechanism
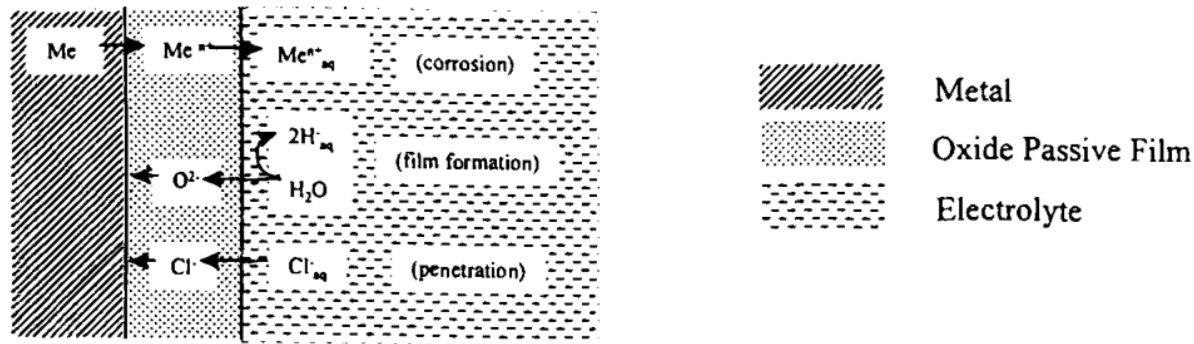

b) Adsorption Mechanism
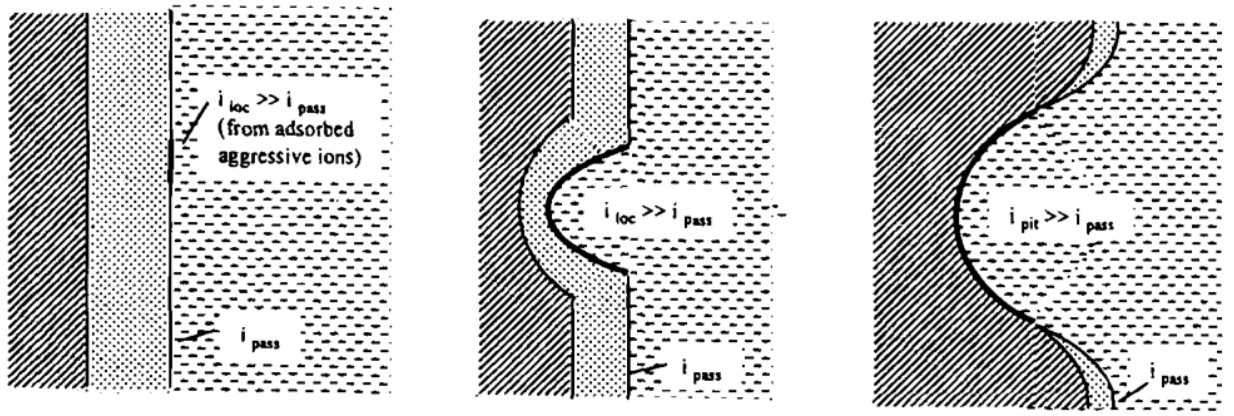

\section{c) Film Breaking Mechanism}

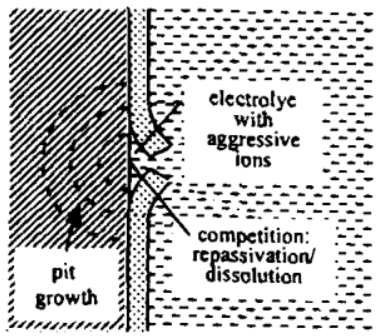

Fig. 4. Schematic diagrams representing pit initiation by (a) penetration, (b) adsorption and thinning, and (c) film breaking. Based on a drawing in Ref. 77 used with permission of the author, H.-H. Strehblow, "Nucleation and Repassivation of Corrosion Pits for Pitting on Iron and Nickel," Werk. Korros., 27, 792 (1976) and Wiley-VCH Verlag GmbH, Weinheim, Germany.

If, as stated by the film-breaking theory, passive film breakdown is frequent and rapid, and pit initiation depends on the generation of conditions needed for a pit to be able to grow, the question then arises as to how those conditions can exist at the instant of film breakdown. As described above, Galvele suggested that a critical factor, $x \cdot i$ is required for pit stability ${ }^{10,17}$ From Galvele's model, a critical $x \cdot i$ value of $10^{-4} \mathrm{~A} / \mathrm{m}$ was determined for the case of Fe. Others have also developed models with a similar factor or made experimental observations that critical values of $x \cdot i$ exist for pit stability, and values of $0.3-0.6 \mathrm{~A} / \mathrm{m}$ for stainless steel ${ }^{25,87,88}$ and $0.2 \mathrm{~A} / \mathrm{m}$ for $\mathrm{Al}^{89}$ have been suggested. If a freshly initiated pit at the instant of film breakdown has a depth on the order of the passive film thickness of $2-5 \mathrm{~nm}$, then extraordinarily high current densities, of about $10^{8} \mathrm{~A} / \mathrm{m}^{2}$, are required for the breakdown to stabilize. (Note that stabilization of dissolution of such an incipient pit is no guarantee that the pit would grow past the metastable 
stage to become a stable growing pit.) Such arguments have led some to conclude that salt films form on the pit surface at very early stages of pit growth. ${ }^{19}$ Current densities as high as $10^{7} \mathrm{~A} / \mathrm{m}^{2}$ have, in fact, been measured on $\mathrm{Al}$ even in a neutral chloride-free solution immediately (a few microseconds) after exposure of a small area by the thin-film breaking technique. ${ }^{90}$ It is possible that the particular sites that are susceptible to pit generation have some occluded aspect, such as being at the bottom of a scratch, so that the effective pit depth is greater than the passive film thickness. The current density required for pit growth stability would be correspondingly lower. Furthermore, as the pit develops, the occlusion associated with the pit itself and its cover, which may be the undermined passive film, will reduce the current density requirement. Regardless, very large current densities are necessary at the instant of film breakdown, and, at least for the case of stainless steel, a high local chloride concentration would be needed to achieve such a high current density. This problem was addressed in one theory of initiation that combines filmbreaking with film penetration. ${ }^{18}$ It is proposed in this theory that chloride migrates to the metal/oxide interface and forms a metal chloride phase that cracks the overlying oxide as a result of its larger specific volume. The chloride phase would then provide a ready source of chloride ions to stabilize pit growth from the very outset of pit development.

Strong evidence for the importance of passive film properties in determining localized corrosion susceptibility was provided by Schmuki and Böhni who studied the effect of monochromatic $(325 \mathrm{~nm})$ illumination on the pitting of $\mathrm{Fe}$ in chloride solution. ${ }^{91}$ Samples tested under illumination, or passivated under illumination and then tested in the dark were found to exhibit greatly increased pitting potentials and incubation times. It was suggested that illumination during passivation permanently altered the semiconducting properties of the passive oxide film. In particular, the bulk doping and surface-state density increased, which may have promoted $\mathrm{OH}^{-}$adsorption and inhibited $\mathrm{Cl}^{-}$adsorption.

Metastable pitting.-Metastable pits are pits that initiate and grow for a limited period before repassivating. Large pits can stop growing for a variety of reasons, but metastable pits are typically considered to be those of micron size at most with a lifetime on the order of seconds or less. Metastable pits can form at potentials far below the pitting potential (which is associated with the initiation of stable pits), and during the induction time before the onset of stable pitting at potentials above the pitting potential. These events are characterized by potential transients in the active direction at open circuit or under an applied anodic current, or anodic current transients under an applied anodic potential. Such transients have been reported in stainless steels $^{92,93}$ and $\mathrm{Al}^{94}$ for many years. However, in the last 10-15 years, considerable effort has gone into systematic studies of metastable pits. Individual metastable pit current transients can be analyzed for pit current density, and stochastic approaches can be applied to groups of metastable pits. It has been shown that when stable pits are small, they behave identically to metastable pits, and in fact are metastable. Stable pits survive the metastable stage and continue to grow, whereas metastable pits repassivate and stop growing for some reason.

An example of metastable pit current transients is given in Fig. 5. Making the assumption that the pits associated with these transients are hemispherical in shape, and that the dissolution process is $100 \%$ current efficient (a poor assumption for the case of $\mathrm{Al}$, in which copious hydrogen evolution locally within pits consumes some of the anodic current), it is possible to determine the pit current density as a function of time. Different shapes of metastable pit current transients may be observed, but initial reports suggested that the current tended to increase with $t^{2}$, so that the current density was approximately constant with time during most of the 
metastable pit growth. ${ }^{25}$ The current density jumped to a higher value just before repassivation. The average metastable pit current density was found to increase with increasing applied potential, suggesting that metastable pit growth is under ohmic control as a result of the resistance associated with the porous pit cover. ${ }^{25}$ Using Sand's equation to predict the time required for salt film precipitation, it was found that the metastable pits repassivated before a salt film precipitated, whereas the current associated with stable pits fluctuated after the time required for salt film precipitation, but then continued to increase. ${ }^{25}$ (It is interesting to note that the $i \cdot t^{1 / 2}$ criterion that comes from Sand's equation is equivalent to an $i \cdot r$ or $i \cdot x$ criterion for these metastable pits.) These observations suggest that metastable pits grow without a salt film and repassivate because of a violent rupture of their passive film covers, which dilutes the local pit environment. If the conditions are such that a salt film can form, the pit has a greater chance of surviving the rupture of the cover and becoming a stable pit because of the buffering action of the salt, which can replenish the pit environment by dissolving.

Other studies looked at metastable current transients in more detail, and found that a distribution of current densities exists for each potential, and that the current may vary with time according to various relationships: $t^{1 / 2}, t$, or $t^{2}{ }^{88,95}$ The distribution was found to shift to higher current densities as the applied potential increased, supporting the view that metastable pits are under ohmic control. ${ }^{95}$

Pistorius and Burstein examined metastable pit growth in a slightly different fashion, and arrived at the conclusion that metastable pit growth is always under mass-transport control, which is only possible because of the barrier to transport created by the pit cover. ${ }^{87,96,97}$ As evidence, they rapidly scanned the potential during metastable pit growth (at $1 \mathrm{~V} / \mathrm{s}$ in the active direction starting after about $1 \mathrm{~s}$ of metastable pit growth) and found that the pit current density did not change with potential (i.e., the current continued to increase with $t^{2}$ despite a large decrease in applied potential). However, these experiments were initiated at extremely high potentials and initial current densities, so it is possible that these pits became salt covered prior to the start of the rapid potential scan. In that case a dependence of pit current density on potential would not be expected. The fact that ensembles of pits measured over a range of applied potentials do exhibit a dependence on potential of pit current densities was explained by suggesting that more open (less occluded) pit sites are activated at higher potentials. ${ }^{87,95}$ In this fashion the average pit current density will increase with potential in spite of mass-transportcontrolled growth if the severity of the transport barrier decreases with potential. In the view of Pistorius and Burstein, stability is associated with sufficient growth such that the pit depth acts as a diffusion barrier, and they developed a critical $i \cdot r$ condition very similar to that determined by Galvele. ${ }^{10,17}$ 


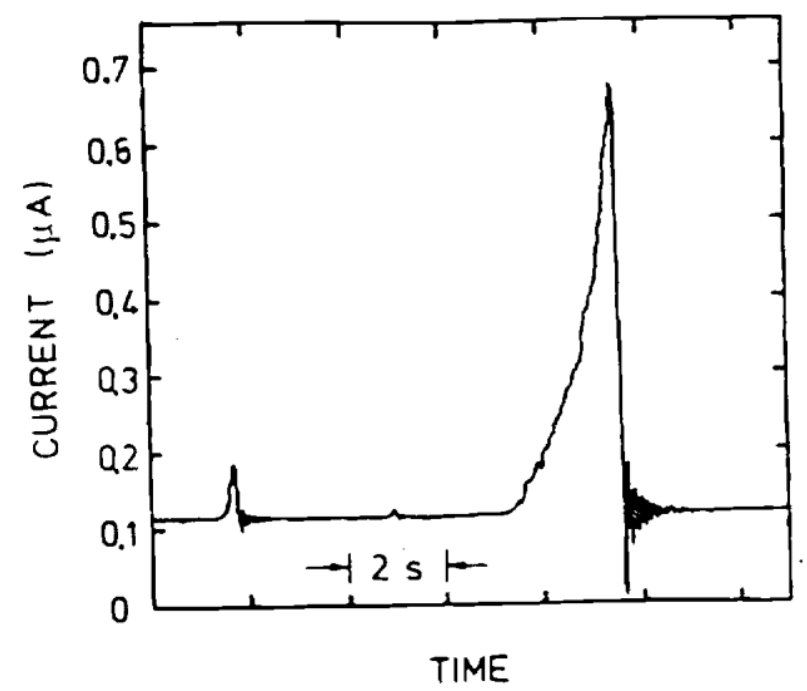

Fig. 5. Typical metastable pit transients observed on stainless steel in chloride solution. From Ref. 25, G. S. Frankel, L. Stockert, F. Hunkler, and H. Boehi, "Metastable Pitting of Stainless Steel," Corrosion, 43, 429 (1987). Copyright by NACE International. All rights reserved by NACE; reprinted with permission.

Williams and coworkers realized that the stochastic approach set out by Shibata could be extended to describe metastable pits, since large ensembles of metastable pits can be generated easily. ${ }^{88,98,99}$ Metastable pits are assumed to nucleate randomly in time and space at a frequency $\lambda$ $\left(\mathrm{cm}^{-2} \mathrm{~s}^{-1}\right)$. Each pit has a probability $\mu\left(\mathrm{cm}^{-2} \mathrm{~s}^{-1}\right)$ of dying, unless it survives beyond a critical age $\tau_{\mathrm{C}}(\mathrm{s})$ at which point it becomes stable. The nucleation frequency of stable pits $\Lambda\left(\mathrm{s}^{-1}\right)$ is then given by

$$
\Lambda=a \lambda \exp \left(-\mu \tau_{c}\right)
$$

where $a$ is the sample area. Note the difference in notation from that of Shibata, who used $\lambda$ to indicate the rate of stable pit nucleation, which is $\Lambda$ in Williams' notation. Underlying this approach is the notion that there is a nonzero chance of stable pit formation if metastable pits form. Pitting potential was determined potentiodynamically, and, in a fashion similar to Shibata, ${ }^{72}$ Williams determines A from the survival probability at a given potential, $P_{\mathrm{S}}(E)$

$$
\Lambda=-v d\left(\ln \left[P_{\mathrm{s}}(E)\right]\right) / d E
$$

where $v$ is the potential ramp rate, and $P_{\mathrm{s}}$ is given by Eq. 2 . Equation 5 simply states that the probability of forming a stable pit is equal to the probability of forming a metastable pit times the probability that the metastable pit will survive to become a stable pit. Figure 6 shows that $\Lambda$ and $\lambda$ have the same dependence on potential (although the rates are orders of magnitude different), indicating that Eq. 5 is indeed valid. ${ }^{88}$ This is an important notion, as it suggests that the stochastically defined susceptibility of a material to the formation of stable pits can be determined by studying the frequency of metastable pits, which are more abundant, and thus easier to observe in large numbers. Such an approach should be used with caution to compare the susceptibility of different materials, however, since, as mentioned above, different sites might be activated at different potentials and the behavior at a given potential might not be indicative of 
the material properties.

Williams goes on to point out that a relationship exists between metastable pit nucleation rate and passive current density for a wide range of surface treatments and experimental parameters. ${ }^{88}$ This suggests that pitting may initiate via a nonlinear feedback mechanism wherein variations in the passive current passing at local surface defects result in local fluctuations in species concentration, which can, under certain conditions, feed back into the local current density to destabilize the system. This is a variation of the film-breaking theory of pit initiation in which the film

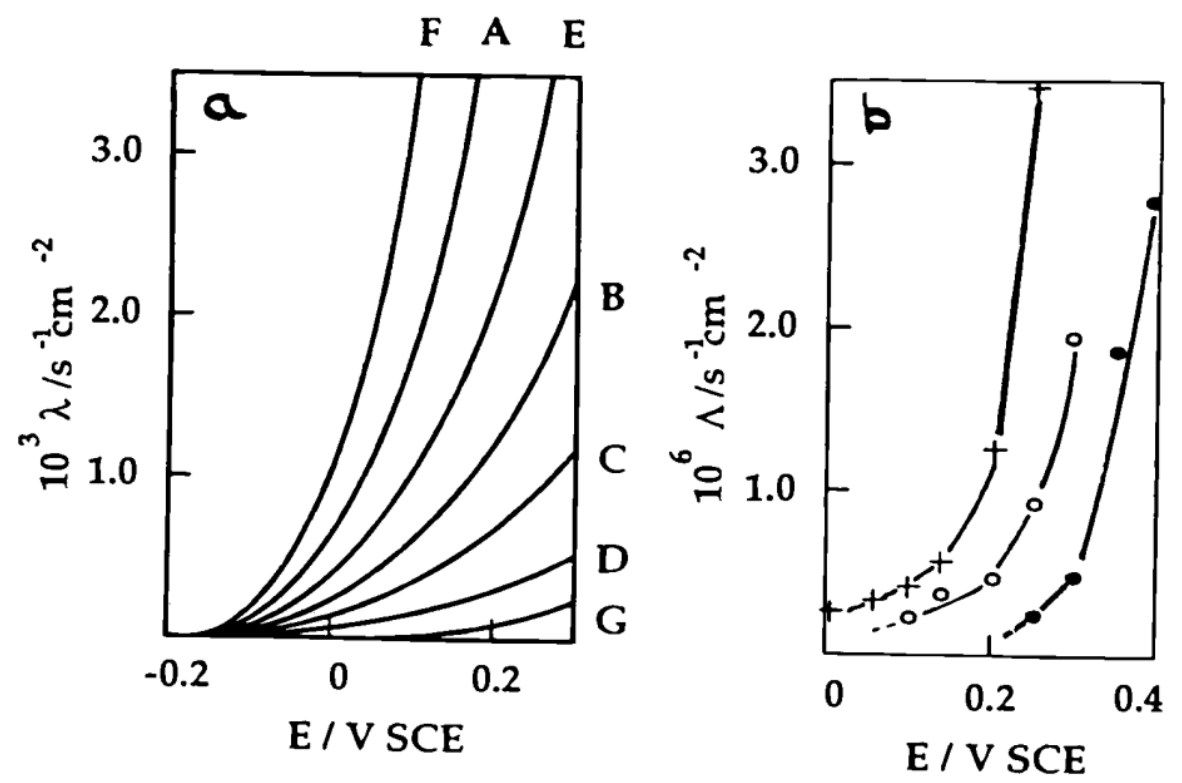

Fig. 6. Variation of (a) metastable pit nucleation frequency $\lambda$. and (b) stable pit nucleation frequency A with potential for different stainless steel alloys. ${ }^{88}$ Reprinted from Corros. Sci., Vol. 36, D. E. Williams, J. Stewart, and P. H. Balkwell, "Nucleation, Growth, and Stability of Micropits in Stainless Steel," Corros. Sci., p. 1213 (1994) with permission from Elsevier Science.

need not necessarily break. Okada has developed similar concepts regarding local fluctuations and pit initiation. ${ }^{100}$

Metastable pitting events at open circuit result in potential transients with a typical shape consisting of a rapid decrease followed by a slow increase. ${ }^{101}$ It was explained by Isaacs that such pitting events draw cathodic current from the interfacial capacitance of the surrounding passive film. ${ }^{102}$ Upon repassivation, the capacitance is slowly recharged.

A recent investigation has studied the possibility that metastable pitting events are correlated, i.e., that one metastable pitting event will enhance the likelihood of subsequent events. ${ }^{103,104}$ A stochastic model was developed with a memory variable that increased the rate of metastable pitting. This memory effect was assumed to decay exponentially with time after each event. Analysis of real current time series by comparison to a Poisson distribution indicated that this correlation can exist to varying extents. It was suggested that the correlation may result from the relaxing conditions inside a recently repassivated pit, changes in the oxide film near the pit or on the pit surface, or the association of pits with discrete microstructural features.

Careful experimentation (using small electrode areas and very quiet electronics) allows the observation of current transients on the nanoampere or even picoampere scale. Whether or 
not the phenomenon associated with the generation of these transients is metastable pitting or should be given a different name is perhaps a matter of semantics. Burstein and Mattin studied the cross section of a $50 \mu \mathrm{m}$ diam stainless steel wire in a low noise system, and observed transients on the order of several hundred pA in height. ${ }^{18}$ The shape of these transients was different than typical metastable pits in that the current increased sharply and then decayed to the background. These peaks were attributed to nucleation and subsequent repassivation events only (no propagation). Suter and Böhni used a microcapillary of diameter as small as $2 \mu \mathrm{m}$ to isolate selected areas on a stainless steel surface. ${ }^{105}$ Transients on the order of $1 \mathrm{nA}$ in height were observed in $\mathrm{Cl}$-free sulfate solution owing to the dissolution of sulfide inclusions. In chloride solutions the pitting potential was found to increase by almost $700 \mathrm{mV}$ as the area of study was decreased from a diameter of 1000 to $50 \mu \mathrm{m}$, apparently as a result of a lower probability for the existence of a critical flaw. Zhu and Williams have recently made extremely sensitive current mapping measurements of stainless steel in chloride solution with a modified atomic force microscope. ${ }^{106}$ At low potentials they found rare locations where the passive current density was slightly higher $(\sim 1 \mathrm{pA})$ than the rest of the sample. Upon subsequent stepping to a higher potential, exactly these areas developed into pits. This is compelling evidence for the feedback mechanism of Williams described above relating passive current density to pit nucleation. On the other hand, such spots may simply have been the locations of sulfide inclusions; no analysis of local composition was performed.

Pit growth.-Pits grow at a rate that depends on material composition, pit electrolyte concentration, and pit bottom potential. The mass-transport characteristics of the pit influence pit growth kinetics through the pit electrolyte concentration, as described above. Pit stability depends upon the maintenance of pit electrolyte composition and pit bottom potential that are at least severe enough to prevent repassivation of the dissolving metal surface at the pit bottom.

In order to understand pit growth and stability, it is essential to ascertain the ratedetermining factors. Pit growth can be controlled by the same factors that can limit any electrochemical reaction: charge-transfer processes (activation), ohmic effects, mass-transport, or some combination of these factors. Using a simple analysis for pit growth under ohmic control, it is possible to determine a series of relationships between current $I$, current density $i$, pit radius $r$ (which is equal to pit depth for a hemispherical pit), time $t$, and potential $E$. If the ohmic potential drop in the pit is controlling, $I \propto r$. Since $i$ can be determined from $I$ and the pit area, $i$ $\propto 1 / r^{2} \propto 1 / r$. From Faraday's law, $i \propto d r / d t$, leading to $r \propto t^{1 / 2}$, and thus $I \propto t^{1 / 2}$ and $i \propto t^{-1 / 2}$. For the case when diffusion of species in the pit controls pit growth, the exact same relationships would be expected since $i \propto 1 / r$ from Fick's law. This can make identification of the ratedetermining step in pitting difficult. For a pit under diffusion control, potential should have no effect on the pit growth rate, while Ohm's law predicts that $i \propto E$, and Tafel's law describing activation control predicts $i \propto \exp E$. However, the nonsteady state nature of deepening pits complicates the clear identification of the $i$ - $E$ relationship.

Determination of the $i-E$ relationship is further complicated by problems associated with accurate measurement of the pit current density. The current measured from a sample held at a fixed potential may come from several pits with unknown active pit surface area. For this situation, one can assume that the current is evenly divided between the pits. ${ }^{107}$ The study of single pits, which have been formed using various experimental approaches, alleviates some of the ambiguity. One of the reasons that metastable pits are so interesting is that metastable pit current transients represent individual pitting events. Other techniques for forming a single pit 
include the exposure of a small area, laser irradiation of a small spot, implantation of an activating species at a small spot, or the use of artificial or single pit electrodes. ${ }^{14,22,108-110}$

As described above, artificial pit electrodes, formed by imbedding a wire in an insulator such as epoxy, allow the study of pit dissolution kinetics in naturally formulated pit environments. Multiple pits are avoided, and only the behavior of the active pit surface is monitored. Artificial pit electrodes have been used extensively to study Fe and stainless steel behavior. An example of the utility of artificial electrodes for understanding pitting corrosion is given in Fig. 7 where the polarization curves for $\mathrm{FeCrNi}$ alloys with and without $2.7 \%$ Mo in a 1 $\mathrm{M} \mathrm{Cl}^{-}$bulk solution are shown. ${ }^{35}$ As described above, one effect of Mo in stainless steel is to ennoble the anodic dissolution reaction in the pit environment. The change in the corrosion potential was approximately equal to the change in pitting potential. ${ }^{35}$ The precipitation of a salt film on an artificial pit electrode surface results in a sudden drop in current, followed by recovery to the diffusion-limited value. ${ }^{111}$ The current response of artificial pit electrodes has been modeled, ${ }^{112,13}$ and their behavior during repassivation used to determine the critical conditions for repassivation. ${ }^{113,114}$ Figure 8 shows the current density of 304 stainless steel (SS) artificial pit electrodes as a function of the surface ion concentration, which was calculated from a model and was decreasing with time, following a step from a high potential where the pit was under transport control and the surface had a salt film to different lower potentials where the pit eventually repassivated. ${ }^{113,114}$ The critical concentration at which the pits repassivated is seen to be about $50-60 \%$ of saturation.

Single pits were generated by Newman and Franz on a standard 304 SS electrode surface masked off to expose a small area. ${ }^{109}$ Under potentiostatic conditions, the current increased approximately with $t^{1 / 2}$ while exhibiting random, sudden increases associated with secondary nucleation events at the edge of the main pit. Downward scanning of the potential from the growth potential (in a fashion similar to, but at a slower rate than that done subsequently by Pistorius and Burstein with metastable pits ${ }^{87}$ ) resulted in a current that decreased almost linearly with potential. This observation is in contrast to the observations of Pistorius and Burstein with metastable pits and is consistent with ohmic-controlled pit growth.

Alkire and Wong created single pits by masking off a small area in the case of stainless steel, ${ }^{21}$ and implanting a small spot of $\mathrm{Fe}$ in the case of $\mathrm{Al}$ samples. ${ }^{14}$ Current was measured during pit growth, and the final pit area was carefully determined after each experiment assuming that the pit was a spherical segment and not necessarily a hemisphere. The current density decreased parabolically, and the values matched closely with a prediction based on masstransport controlled pit growth. As in the Pistorius and Burstein experiments, however, the applied potential was quite high.

Nonelectrochemical techniques are useful for the study of pit growth because they eliminate several problems: the need to determine the current from a single pit, assumptions regarding active pit surface area, and complications associated with hydrogen evolution within the pits that can consume a reasonable fraction of the anodic pit current density for pits in Al. ${ }^{115}$ Hunkeler and Böhni used the time for pits to perforate $\mathrm{Al}$ foils of varying thickness as a means to determine pit growth rate of the fastest growing pits. ${ }^{116}$ For pits in Al foils of thickness 0.05-0.2 $\mathrm{mm}$ at a fixed applied potential, they found the time dependence of pit depth, $d$, and current density, $i$, described above for ohmic control, i.e., $d \propto t^{1 / 2}$ and $i \propto t^{-1 / 2}$, and expressed the relationship as

$$
i_{\mathrm{p}}=i_{\mathrm{p}}^{\mathrm{o}} t^{-0.5}
$$


where $i_{\mathrm{p}}^{\circ}$ is the pit current density for $t=1 \mathrm{~min}$, if $t$ is in min. The $i$ - $E$ relationship can thus be expressed by the dependence of $i_{\mathrm{p}}^{\circ}$ on potential. It was found that $i_{\mathrm{p}}^{\circ}$ increased with increasing potential and chloride concentration. Pit growth rate was found to be under ohmic control as the electrolyte resistance had a direct effect on perforation time. The effect of various anions on pit growth was determined by exchanging the electrolyte shortly after pit initiation. ${ }^{116}$ Nitrate and chromate ions were found to be inhibiting (they increased perforation time), while other anions reduced the perforation time because of a decrease in electrolyte resistance. The same technique was used under slightly different conditions in another study and the pit growth rate was found to be independent of applied potential. ${ }^{117}$ It was suggested that the difference was partly a result of eliminating crevices. The foil penetration technique has not been widely used, but it appears to be a powerful tool for studying pit growth kinetics.

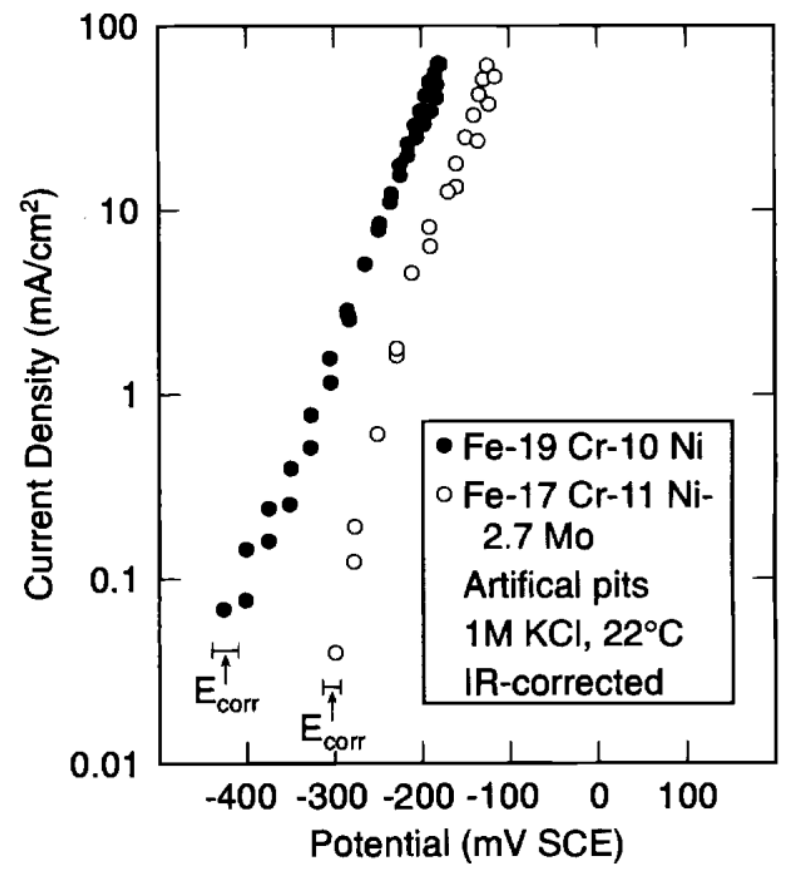

Fig. 7. IR-corrected dissolution kinetics in ortificiol pit electrodes. (From Corros. Sci., Vol. 25, R. C. Newman, "The Dissolution and Passivation Kinetics of Stainless Alloys Containing Molybdenum. II. Dissolution Kinetics in Artificial Pits," p. 341 (1985). Reprinted with permission of Elsevier Science.)

Another nonelectrochemical approach to pitting involves the study of $2 \mathrm{D}$ pits in thin film samples. ${ }^{50,115,118,119}$ Pits in thin metallic films with thickness on the order of 10-1000 nm rapidly penetrate the metal, reach the inert substrate, and proceed to grow outward in a 2D fashion with perpendicular sidewalls. The measurement of pit wall velocity from the analysis of magnified images of the growing 2D pits provides a simple and direct means for determination of pit current density via Faraday's law, with no need for assumptions. Since the pit depth is limited by the metal film thickness, pits in thin films grow at steady state with no increase in ohmic path or diffusion length with time as is the case described above for pits in bulk samples. As a result, 2D pits in thin films exhibit a pit current density that is constant with time at a given applied potential. This steady-state aspect of pitting in thin-film samples allows unambiguous determination of the current-density/potential relationship. An example is given in Fig. 9 for 
Permalloy (Ni-20Fe) films in $0.1 \mathrm{M} \mathrm{NaCl} .{ }^{118}$ These curves are essentially polarization curves of the active pit surface in the pit environment. The typical form for the polarization curve of a thin film pit includes a region at low potentials where the current density is almost linearly dependent on applied potential followed by a region at high potential where the pit current density reaches a limiting value, and pitting is mass-transport limited. Another consequence of the constant pit depth is the finding that the repassivation potential and the lowest pit current density at which a pit can grow are extremely reproducible. It is therefore possible with pits in thin films to accurately assess the critical conditions for pit stability.

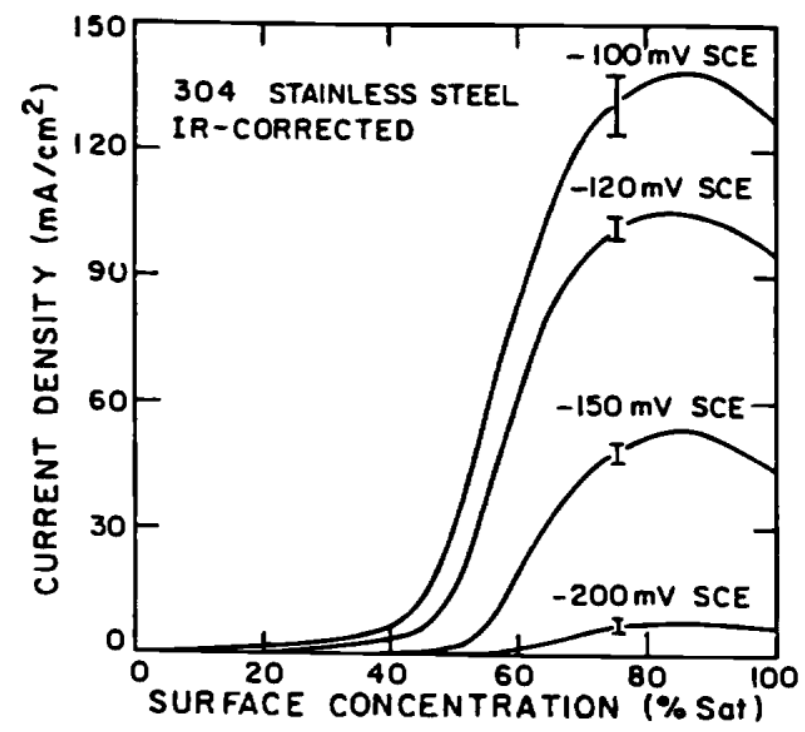

Fig. 8. Current density as a function of calculated surface concentration and applied potential for 304 stainless steel following a step from a higher potential. From Ref. 113, G. T. Gaudet, W. T. Mo, T. A. Hatton, J. W. Tester, J. Tilley, H. S. Isaacs, and R. C. Newman, "Mass Transfer and Electrochemical Kinetic Interactions in Localized Pitting Corrosion," AlChEJ., Vol. 32, p. 949 (1986).

Such an approach was used to study the effect of alloying additions in sputter-deposited Al binary alloys,${ }^{50}$ which, as described above, exhibit remarkably high values of pitting potential. Figure 10 shows the pit polarization curves for 2D pits in thin film Al-Nb of varying composition. It is clear that the pit dissolution kinetics are considerably ennobled relative to the pure Al sample. This type of analysis for several different Al binary alloy systems indicated that the improvement in pitting potential associated with alloying of Al can be largely accounted for by effects on the pit dissolution kinetics. Essentially, higher potentials are required to achieve the high current densities necessary to prevent repassivation and thus to stabilize pit growth. The influence of alloying on the composition of the passive film is small in comparison to the effect on pit growth kinetics.

For any growing pit or crevice, the pit bottom potential is lower than the outside potential as a result of the ohmic potential drop associated with current flowing through the pit solution of finite resistance. For systems in which the metal exhibits active/passive behavior in the bulk environment, such as iron in sulfuric acid, the ohmic potential drop can stabilize localized corrosion in a sample held at a potential nominally in the passive region by depressing the local pit potential far enough that it resides in the active region. ${ }^{120}$ Under those conditions, the pit current density is large and stabilizes the attack by creating the requisite potential drop to keep 
the potential of the occluded area in the active region. However, in most systems of major practical importance, such as $\mathrm{Al}$ and stainless steel in neutral chloride environments, the ohmic potential drop decreases the potential available at the pit surface to drive electrochemical reactions and thus destabilizes the pitting reaction. In these systems, the changes in local pit environment ( $\mathrm{pH}$ and chloride concentration) are key to pit stability. Pit growth at low potentials below the range of limiting pit current densities is controlled by a combination of ohmic, chargetransfer, and concentration overpotential factors. At high potentials, mass transport may be ratecontrolling. Ultimately, however, mass transport determines the stability of pits even at lower potentials because the local environment controls passivation.

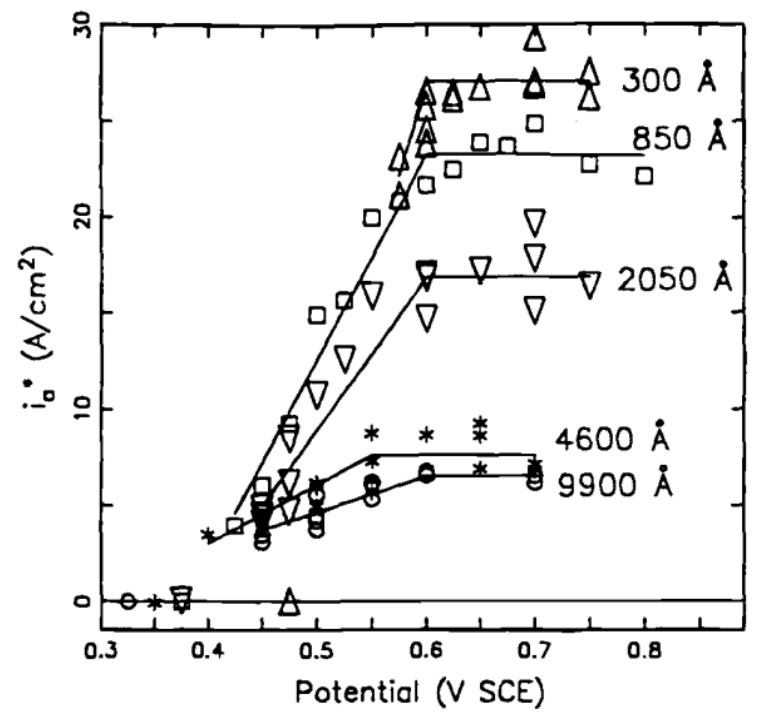

Fig. 9. Anodic pit current density as a function of growth potential and film thickness for Ni-20Fe thin films in 0.1 $\mathrm{M} \mathrm{NaCl} .{ }^{118}$ Reprinted with permission of the Journal of the Electrochemical Society.

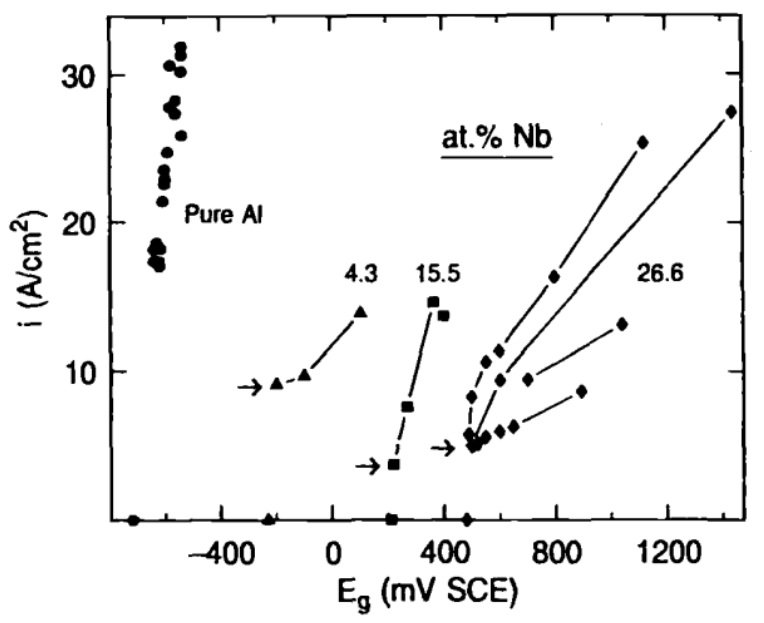

Fig. 10. Anodic pit current density as a function of growth potential for pure $\mathrm{Al}$ and $\mathrm{AlNb}$ alloys in $0.1 \mathrm{M} \mathrm{NaCl}^{50}$ Reprinted with permission.

\section{Summary}


Pitting corrosion is a complex but important problem that is at the root of many corrosion failures. It has been studied in detail for many years, yet crucial phenomena remain unclear. A balanced view of the critical factors was attempted in this review. Pit growth may be controlled by the same factors that control any electrochemical reaction: charge-transfer processes, ohmic effects, and mass-transport considerations. Pit stability is determined by the maintenance of conditions at the pit surface severe enough to prevent repassivation. The role of many of the environmental and material parameters that are critical to the pitting process, such as potential, alloy composition, electrolyte concentration, and temperature, can be explained by their effects on pit growth stability for passive metals of technological importance, such as stainless steel and aluminum alloys. The influences of the passive film characteristics on the pitting process seem to be secondary in nature. The mechanism of the very initiation of pitting, or breakdown of the otherwise protective passive film, is not clearly understood, but may not be of ultimate importance to pitting corrosion. The study of metastable pitting has provided unique opportunities for understanding pitting corrosion since metastable pits involve initiation, growth, and repassivation in short, discrete, and plentiful events. It is easier to address the stochastics of pitting using large numbers of metastable pits than by generating many stable pits. The signal associated with each metastable pitting event can be analyzed to determine pit current density, which allows determination of the electrochemical kinetics of dissolution in pits and assessment of the rate-controlling steps. Finally, repassivation of metastable pits provides information on the stability criteria for pit growth. In summary, the large majority of experimental evidence suggests that pitting corrosion is controlled by factors relating to pit growth stability.

\section{Acknowledgments}

Portions of this work and the preparation of this manuscript were supported by the United States Air Force Office of Scientific Research contracts F49620-96-1-0479 and F49620-96-0042 administered by Major H. De Long. Discussions with H. Isaacs and S. Smialowska are greatly appreciated.

Manuscript submitted July 7, 1997; revised manuscript received December 5, 1997. This was Paper 144 presented at the Montreal, Quebec, Canada, Meeting of the Society, May 4-9, 1997.

The Ohio State University assisted in meeting the publication costs of this article.

\section{REFERENCES}

1. Z. Szklarska-Smialowska, Pitting Corrosion of Metals, NACE, Houston, TX (1986).

2. Localized Corrosion, NACE-3, R. W. Staehle, B. F. Brown, J. Kruger, and A. Agarwal, Editors, NACE, Houston, TX (1974).

3. Advances in Localized Corrosion, NACE-9, H. Isaacs, U. Bertocci, J. Kruger, and S. Smialowska, Editors, NACE, Houston, TX (1990).

4. Corrosion Chemistry within Pits, Crevices, and Cracks, A. Turnbull, Editor, HMSO Books, London (1987).

5. Critical Factors in Localized Corrosion, G. S. Frankel and R. C. Newman, Editors, PV 92-9, The Electrochemical Society Proceedings Series, Pennington, NJ (1992).

6. Critical Factors in Localized Corrosion II, P. M. Natishan, R. G. Kelly, G. S. Frankel, and R. C. Newman, Editors, PV 95-15, The Electrochemical Society Proceedings Series, Pennington, NJ (1995).

7. Passivity of Metals, R. P. Frankenthal and J. Kruger, Editors, The Electrochemical Society Corrosion Monograph Series, Princeton, NJ (1978).

8. P. Schmuki, J. Fraser, C. M. Vitus, M. J. Graham, and H. S. Isaacs, J. Electrochem. Soc., 143, 3316 (1996).

9. H. P. Leckie and H. H. Uhlig, J. Electrochem. Soc., 113, 1262 (1966).

10. J. R. Galvele, Corros. Set, 21, 551 (1981).

11. Annual Book of ASTM Standards, G48-92, p. 189, ASTM, Philadelphia, PA (1994).

12. R. G. Kelly, in Proceedings of Corrosion/97, Research Topical Symposia, F. Mansfeld, W. H. Smyrl, M. 
Kendig, and B. Shaw, Editors, p. 81, NACE, Houston, TX (1997).

13. A. Turnbull, in Advances in Localized Corrosion, H. Isaacs, U. Bertocci, J. Kruger, and S. Smialowska, Editors, NACE-9, p. 359, NACE, Houston, TX (1990).

14. K. P. Wong and R. C. Alkire, J. Electrochem. Soc., 137, 3010(1990).

15. J. Mankowski and Z. Szklarska-Smialowska, Corros. Sci., 15, 493 (1975).

16. H. S. Isaacs, J.-H. Cho, M. L. Rivers, and S. R. Sutton, J. Electrochem. Soc., 142, 1111 (1995).

17. J. R. Galvele, J. Electrochem. Soc., 122, 465 (1976).

18. G. T Burstein and S. P. Mattin, in Critical Factors in Localized Corrosion II, P. M. Natishan, R. J. Kelly, G. S. Frankel, and R. C. Newman, Editors, PV 95-15, p. 1, The Electrochemical Society Proceedings Series, Pennington, NJ (1995).

19. T R. Beck and R. C. Alkire, J. Electrochem. Soc., 126, 1662 (1979).

20. T R. Beck, J. Electrochem. Soc., 129, 2413 (1982).

21. R. C. Alkire and K. P. Wong, Corros. Sci., 28, 411 (1988).

22. R. C. Alkire and M. Feldman, J. Electrochem. Soc., 135, 1850 (1988).

23. Annual Book of ASTM Standards, G61-86, p. 238, ASTM, Philadelphia, PA (1994).

24. B. E. Wilde and E. Williams, Electrochim. Acta., 16, 1971(1971).

25. G. S. Frankel, L. Stockert, F Hunkeler, and H. Boehni, Corrosion, 43, 429 (1987).

26. B. E. Wilde, in Localized Corrosion, R. W Staehle, B. F Brown, J. Kruger, and A. Agrawal, Editors, NACE-3, p. 342, NACE, Houston, TX (1974).

27. M. Yasuda, F. Weinberg, and D. Tromans, J. Electrochem. Soc., 137, 3708 (1990).

28. N. Sridhar and G. A. Cragnolino, Corrosion, 49, 885 (1993).

29. N. G. Thompson and B. C. Syrett, Corrosion, 48, 649 (1992).

30. J. Horvath and H. H. Uhlig, J. Electrochem. Soc., 115, 791 (1968).

31. H. Ogawa, H. Omata, I. Itoh, and H. Okada, Corrosion, 52 (1978).

32. K. Hashimoto, K. Asami, and K. Teramoto, Corros. Sci., 19, 3 (1979).

33. M. Sakashita and N. Sato, Corros. Sci., 17, 473 (1977).

34. M. Urquidi and D. D. Macdonald, J. Electrochem. Soc., 132, 555(1985).

35. R. C. Newman, Corros. Sci., 25, 341 (1985).

36. P. Marcus, in Corrosion Mechanisms in Theory and Practice, P. Marcus and J. Oudar, Editors, p. 239, Marcel Dekker, Inc., New York (1995).

37. A. J. Sedriks, in Advances in Localized Corrosion, H. Isaacs, U. Bertocci, J. Kruger, and S. Smialowska, Editors, NACE-9, p. 253, NACE, Houston, TX (1990).

38. A. J. Sedriks, Corrosion of Stainless Steels, Wiley-Interscience, New York (1996).

39. R. C. N and T. Shahrabi, Corros. Sci., 27, 827 (1987).

40. G. S. Frankel, M. S. Russak, C. V. Jahnes, M. Mirzamaani, and V. A. Brusic, J. Electrochem. Soc., 136, 1243 (1989).

41. W. C. Moshier, G. D. Davis, J. S. Ahearn, and H. F.Hough, J. Electrochem. Soc., 133, 1063 (1986).

42. W. C. Moshier, G. D. Davis, J. S. Ahearn, and H. F.Hough, J. Electrochem. Soc., 134, 2677 (1987).

43. W. C. Moshier, G. D. Davis, and G. O. Cote, J. Electrochem. Soc., 136, 356 (1989).

44. W. C. Moshier, G. D. Davis, T. L. Fritz, and G. O. Cote, J. Electrochem. Soc., 137, 1317 (1990).

45. R. B. Inturi and Z. Szklarska-Smialowska, Corros. Sci., 34, 1201 (1993).

46. I. L. Muller and J. R. Galvele, Corros. Sci., 17, 179 (1977).

47. E. McCafferty and P. M. Natishan, in Critical Factors in Localized Corrosion, G. S. Frankel and R. C. Newman, Editors, PV 92-9, p. 299, The Electrochemical Society Proceedings Series, Pennington, NJ (1992).

48. Z. Szklarska-Smialowska, Corros. Sci., 33, 1193 (1992).

49. G. D. Davis, B. A. Shaw, B. J. Rees, and C. A. Pecile, Surf. Int. Anal., 23, 609 (1995).

50. G. S. Frankel, R. C. Newman, C. V. Jahnes, and M. A. Russak, J. Electrochem. Soc., 140, 2192 (1993).

51. G. S. Eklund, J. Electrochem. Soc., 121, 467 (1974).

52. G. Wranglen, Corros. Sci., 14, 331 (1973).

53. S. E. Lott and R. C. Alkire, J. Electrochem. Soc., 136, 973 (1989).

54. C. S. Brossia and R. G. Kelly, in Critical Factors in Localized Corrosion II, P. M. Natishan, R. J. Kelly, G. S. Frankel, and R. C. Newman, Editors, PV 95-15, p. 201, The Electrochemical Society Proceedings Series, Pennington, NJ (1995).

55. R. C. Newman, H. S. Isaacs, and B. Alman, Corrosion, 38, 261 (1982).

56. P. Marcus, A. Teissier, and J. Oudar, Corros. Sci., 24, 259 (1984).

57. K. Kowal, J. DeLuccia, J. Y Josefowicz, C. Laird, and G. C. Farrington, J. Electrochem. Soc., 143, 2471 (1996). 
58. R. M. Eynders, C.-H. Paik, R. Ke, and R. C. Alkire, J. Electrochem. Soc., 141, 1439 (1994).

59. A. P. Bond, G. F Boiling, and H. A. Domian, J. Electrochem. Soc., 13, 773 (1996).

60. J. C. Scully, D. E. Peebles, J. A. D. Romig, D. R. Frear, and C. R. Hills, Met. Trans. A, 23A, 2641 (1992).

61. J. O. Park, C.-H. Paik, and R. C. Alkire, in Critical Factors in Localized Corrosion II, P. M. Natishan, R. J. Kelly, G. S. Frankel, and R. C. Newman, Editors, PV 95-15, p. 218, The Electrochemical Society Proceedings Series, Pennington, NJ (1995).

62. R. G. Buchheit, R. P. Grant, P. F. Hlava, B. McKenzie, and G. L. Zender, J. Electrochem. Soc., 144, 2621 (1997).

63. B. Baroux, in Corrosion Mechanisms in Theory and Practice, P. Marcus and J. Oudar, Editors, p. 265, Marcel Dekker, Inc., New York (1995).

64. P. E. Arnvig and A. D. Bisgard, Paper 437 presented at Corrosion '96, NACE (1996).

65. P. E. Arnvig and R. M. Davison, in Proceedings of the 12th International Corrosion Congress, Paper No. 209, p. 1477, NACE (1993).

66. R. J. Brigham and E. W. Tozer, Corrosion, 29, 33 (1973).

67. R. J. Brigham and E. W. Tozer, Corrosion, 30, 161 (1974).

68. R. Qvarfort, Corros. Sci., 28, 135 (1988).

69. R. Qvarfort, Corros. Sci., 29, 987 (1989).

70. N. J. Laycock, M. H. Moayed, and R. C. Newman, in Critical Factors in Localized Corrosion II, P. M Natishan, R. J. Kelly, G. S. Frankel, and R. C. Newman, Editors, PV 95-15, p. 68, The Electrochemical Society Proceedings Series, Pennington, NJ (1995).

71. R. C. Newman, Personal communication.

72. T. Shibata and T. Takeyama, Corrosion, 33, 243 (1977).

73. S. B. deWexler and J. R. Galvele, J. Electrochem. Soc., 121, 1271 (1974).

74. C. Edeleanu and U. R. Evans, Trans. Faraday Soc., 47, 1121 (1951).

75. M. W. Kendig, A. J. Davenport, and H. S. Isaacs, Corros. Sci., 34, 41 (1993).

76. Alternatives to Chromium for Metal Finishing, Report No. 0273RE95, National Center for Manufacturing Sciences, Ann Arbor, MI (1995).

77. H.-H. Stehblow, Werkst. Korros., 27, 792 (1976).

78. H.-H. Strehblow, in Corrosion Mechanisms in Theory and Practice, P. Marcus and J. Oudar, Editors, p. 201, Marcel Dekker, Inc., New York (1995).

79. T. P. Hoar, Corros. Sci., 5, 279 (1965).

80. P. Marcus and J.-M. Herbelin, Corros. Sci., 34, 1123 (1993).

81. J. A. Bardwell, B. MacDougall, and G. I. Sproule, J. Electrochem. Soc., 136, 1331 (1989).

82. C. Y. Chao, L. F. Lin, and D. D. Macdonald, J. Electrochem. Soc., 128, 1187 (1981).

83. L. F. Lin, C. Y. Chao, and D. D. Macdonald, J. Electrochem. Soc., 128, 1194 (1981).

84. H. H. Uhlig, J. Electrochem. Soc., 97, 215C (1950).

85. N. Sato, Electrochim. Acta, 16, 1683 (1971).

86. J. A. Richardson and G. C. Wood, Corros. Sci., 10, 313 (1970).

87. P. C. Pistorius and G. T. Burstein, Philos. Trans. R. Soc., Lond. A, 341, 531(1992).

88. D. E. Williams, J. Stewart, and P. H. Balkwill, Corros. Sci., 36, 1213 (1994).

89. S. T. Pride, J. R. Scully, and J. L. Hudson, J. Electrochem. Soc., 141, 3028 (1994).

90. G. S. Frankel, C. V. Jahnes, V. Brusic, and A. J. Davenport, J. Electrochem. Soc., 142, 2290 (1995).

91. P. Schmuki and H. Bohni, Electrochim. Acta, 40, 775 (1995).

92. N. Pessall and C. Liu, Electrochim. Acta, 16, 1987 (1971).

93. Y. Hisamatsu, T. Yoshii, and Y. Matsumuraq, in Localized Corrosion, R. W. Staehle, B. F. Brown, J. Kruger, and A. Agrawal, Editors, NACE-3, NACE, Houston, TX (1974).

94. G. C. Wood, W. H. Sutton, J. A. Richardson, T. N. K. Riley, and A. G. Malherbe, in Localized Corrosion, R. W. Staehle, B. F Brown, J. Kruger, and A. Agrawal, Editors, p. 526, NACE, Houston, TX (1974).

95. H. Ezuber and R. C. Newman, in Critical Factors in Localized Corrosion, G. S. Frankel and R. C. Newman, Editors, PV 92-9, p. 120, The Electrochemical Society Proceedings Series, Pennington, NJ (1992).

96. P. C. Pistorius and G. T. Burstein, Corros. Sci., 36, 525 (1994).

97. P. C. Pistorius and G. T. Burstein, Corros. Sci., 33, 1885 (1992).

98. D. E. Williams, C. Westcott, and M. Fleischmann, J. Electrochem. Soc., 132, 1796 (1985).

99. P. H. Balkwill, C. Westcott, and D. E. Williams, Mater. Sci. For., 44 \& 45, 299 (1989).

100. T. Okada, in Critical Factors in Localized Corrosion, G. S. Frankel and R. C. Newman, Editors, PV 92-9, p.65, The Electrochemical Society Proceedings Series, Pennington, NJ (1992). 
101. M. Hashimoto, S. Miyajima, and T. Murata, Corros. Sci., 33, 885 (1992).

102. H. S. Isaacs, Corros. Sci., 34, 525 (1993).

103. B. Wu, J. R. Scully, J. L. Hudson, and A. S. Mikhailov J. Electrochem. Soc., 144, 1614 (1997).

104. T. T. Lunt, S. T. Pride, J. R. Scully, J. L. Hudson, and A. S. Mikhailov, J. Electrochem. Soc., 144, 1620(1997).

105. H. Bohni, T. Suter, and A. Schreyer, Electrochim. Acta, 40, 1361 (1995).

106. Y. Zhu and D. E. Williams, J. Electrochem. Soc., 144, L43 (1997).

107. Z. Szklarska-Smialowska and J. Mankowski, Corros. Sci., 12, 925 (1972).

108. D. W. Buzza and R. C. Alkire, J. Electrochem. Soc., 142, 1104 (1995).

109. R. C. Newman and E. M. Franz, Corrosion, 40, 325 (1984).

110. H.-H. Strehblow and J. Wenners, Z. Phys. Chem. Neue Folge, 98, 199 (1975).

111. H. S. Isaacs and R. C. Newman, in Corrosion and Corrosion Protection, R. P. Frankenthal and F. Mansfeld,Editors, PV 81-8, p. 120, The Electrochemcial Society Proceedings Series, Pennington, NJ (1981).

112. J. W. Tester and H. S. Isaacs, J. Electrochem. Soc., 122, 1438 (1975).

113. G. T. Gaudet, W. T. Mo, T. A. Hatton, J. W. Tester, J. Tilly, H. S. Isaacs, and R. C. Newman, AIChE J., 32 , 949 (1986).

114. U. Stemsmo and H. S. Isaacs, J. Electrochem. Soc., 140, 643 (1993).

115. G. S. Frankel, Corros. Sci., 30, 1203 (1990).

116. F. Hunkeler and H. Bohni, Corrosion, 37, 645 (1981).

117. W. K. Cheung, P. E. Francis, and A. Tumbull, Mater. Sci. For., 192-194, 185 (1995).

118. G. S. Frankel, J. O. Dukovic, B. M. Rush, V. Brusic, and C. V. Jahnes, J. Electrochem. Soc., 139, 2196 (1992).

119. G. S. Frankel, J. R. Scully, and C. V. Jahnes, J. Electrochem. Soc., 143, 1834 (1996).

120. H. W. Pickering, Corros. Sci., 29, 325 (1989). 